\title{
Several Advices on the Employment Guidance Works for the Undergraduates
}

\author{
Yaxiu Liu \\ School of Electronic and Information Engineering, North China Institute of Science and Technology, Yanjiao \\ Development Zone, Sanhe County, 065201, China \\ liuyaxiu1975@ncist.edu.cn
}

\begin{abstract}
Aiming at the urgent employment situation of the university graduates, the author analyzed some existing problems in current college employment guidance works, and put forward some corresponding measures. There are many reasons for the problem of difficult for the undergraduates to be employed. The composition of the employment guidance staffs should be diversified, they should include experienced professional teachers; the employment guidance system should be established and improved, which should exist at different levels of the employment of the students; the employment guidance work included the career planning education, employment idea education, employment strategy and skill education, etc.

Index Terms - Employment Guidance, Advices, Works.
\end{abstract}

\section{I . Introduction}

In recent years, due to the impact of the economic crisis, college enrollment, talents and other factors of the university graduates, the employment situation is very serious, has caused extensive concern of the whole society.

In this regard, the school of the university graduates employment guidance work plays an important role. However, at present, there are some shortcomings in this regard many schools, did not play its potential.

In this paper, the author's own practical experience based on, the current status of college employment guidance work and existing problems are analyzed, and then puts forward the corresponding improvement measures. This paper has important significance to promote the employment of University students.

\section{II . Problems and suggestions}

At present, in most schools, engaged in the work of employment guidance teachers are the instructor, and many counselors, social experience shallow, most has the theoretical knowledge, but the practice ability is insufficient, resulting in employment guidance work effect is not good.

Aiming at this point, suggested that the school should expand the scope of employment guidance staff, diversification, such as part of experienced professional teachers as the employment guidance work, at the same time, a documented appointment system. Because the professional teachers could understand the employment situation more professionally and thoroughly.
In addition, to do a good job in employment guidance, rely on the usual accumulation of every little bit, therefore, is currently engaged in the work of employment guidance personnel should constantly improve their work ability, actively collect relevant employment information, in-depth understanding of the psychology of the students. In the aspect of collecting employment information, first of all, education graduates collect employment information; secondly, open up multiple channels, such as by professional teachers, alumni and other forms.

\section{III . The establishment of employment guidance system}

Employment guidance system mainly includes:

(1) Establishment of teacher employment guidance system.

(2) Establishment of the appropriate employment guidance staff, including full-time and part-time staff.

(3) Establishment of employment guidance work tasks and goals, break down tasks, to implement, and regularly and irregularly on the employment work.

(4) The construction of the social practice system. At present, the employing units generally require students to have some working experience. It is also a bottleneck for graduates employment. Therefore, suggested that the school to strengthen the social practice system construction work, using a variety of resources to create social practice opportunities for students. For example, the usual consciously guide and encourage more students to participate in practical activities: such as various competitions, scientific research, production practice, work-study, social survey, various cultural and sports activities, to strengthen the practical ability of students.

At present, most of the schools that employment is the fourth grade students, University. Based on this concept, the school is often the only employment guidance to the fourth grade students, employment guidance and lack of systematic and integrity.

In fact, the employment guidance work should be started from the first grade university, through the whole university stage, do the long. The concrete contents include:

4.1 occupation career planning education. Low grade students education suitable for their own occupation career planning. Understanding of their own specific circumstances, including the advantages and disadvantages, hobbies, and have an accurate positioning of their own, thus establishing suitable employment target. 
In addition, let the students for future employment prepare actively, conscientiously study and professional knowledge, master the necessary skills, including professional ability, computer, foreign language, the ability to relate to others. Now the unit is more pragmatic, hope can take charge as chief of, so the requirements of professional knowledge is more solid. If the mold design professional students, can skillfully use AutoCAD, Pro/E, UG and other computer software.

4.2 the concept of employment education. Starting from the low grade, education students to have a correct concept of employment, establish the employment expectation appropriate value, has a positive, active attitude in the course of employment.

Education of students with a long-term vision, not too much value on the initial period of employment treatment, should be considered to solve the main contradiction, rely on the accumulation, and constantly improve their own ability.

According to their own actual situation, choose the place of work and work units. Some people fit in the big city, but some people fit in the small town, one for large state-owned units, there are suitable for small private enterprises.

To prepare for graduate students, educators should they cannot throw the helve after the hatchet -- namely in the process to prepare for the exam, should also be looking for work. Many students are completely given up looking for work, thus missed the good opportunity. What are the two possibilities: even if he is very serious, hard to prepare for the exam, but may also lose. So we're looking for their " posterior " : on the one hand earnestly preparing for the exam, on the other hand also actively looking for a job, if you can find a receiver unit before the exam, so their psychological pressure will be eased, but easier to play at a high level in the exam. Some people may say: " one can not be in two ", finding a job will be a waste of time. That is the theory, but now the recruitment of frequency is not high, basically every one or two weeks, so it won't waste much time. And if all day to read a book for the exam, so the efficiency is not high. Can borrow in job opportunities for proper regulation, it helps to improve review efficiency.

4.3 of high school students, employment strategy and skill education.

First of all, using lectures, consulting and other forms of employment, the employment situation of policy propaganda introduction, employment information. Encourage the students to participate in the recruitment, understanding of employer needs, learn from other job seekers.

Secondly, the initiative to broaden employment -- the employment direction of surface is not confined to their own specialty, efforts should be made to seek the relevant professional and all units of interest. Just like a unit, to take the initiative to resume. Because the majority of units to see is the basic quality, as long as the quality is high, if not professional counterparts, through in-service training, also can compensate for the. In addition, many students college entrance examination are blindly fill, at that time many people don't know their strengths, namely, a lot of people 's potential and the speciality is not consistent, so looking for work, can also according to the interest to look for. The worst result is not accepted this to his unit, the loss is small, but the increase of a chance, is also an exercise.

Third, to teach some practical, feasible employment skills of the students, such as a resume cast, should take the initiative to call to ask for 10 days, because the employer may receive hundreds of resumes every day, may never see your resume, if you give a phone unit, the unit that you are sincere specifically, it will read your resume, so, their opportunity naturally bigger. In addition, should highlight their ability to practice your resume, such as a variety of extracurricular activities, participate in internships, part-time work.

\section{IV . Conclusions}

Aiming at the urgent employment situation of the university graduates, the author analyzed some existing problems in current college employment guidance works, and put forward some corresponding measures. There are many reasons for the problem of difficult for the undergraduates to be employed. The composition of the employment guidance staffs should be diversified, they should include experienced professional teachers; the employment guidance system should be established and improved, which should exist at different levels of the employment of the students; the employment guidance work included the career planning education, employment idea education, employment strategy and skill education, etc.

\section{Reference}

[1] Li Xiangming. Discussion on Countermeasures of the employment of college graduates under the financial crisis. Jilin education. 2010, 10:2021

[2] Liu Yuecheng, Zhang Linan. The employment status of graduates, strengthening occupation guidance effectiveness. Journal of social science of Jiamusi University. 2010, 28 ( 4 ): 108110

[3] Jin Yeying of the employment of college graduates and Countermeasures . China forestry education, 2007.2.

[4] $\mathrm{Wu}$ Chengguo, the employment of college graduates from the perspective of the new . Journal of Southwest University for Nationalities ( HUMANITIES AND SOCIAL SCIENCES EDITION ), 2008.7.

[5] Zang Kobayashi . Construction of college graduates' employment mechanism . Journal of Southwest University for Nationalities ( HUMANITIES AND SOCIAL SCIENCES EDITION ), 2006.4.

[6] Xiong Jian. Some college graduates' employment in financial crisis on . Journal of Jiangxi Institute of Education ( SOCIAL SCIENCE ), 2009.4.

[7] Li Jun. Current situation and Countermeasure of on university occupation guidance. The employment of college students in China, 2008, ( 13 ).

[8] Wang Lingyun, Yu industry Jane, Huang Yong. Students employment orientation and employment intentions survey research. Chinese college students' employment, 2008, ( 13 ).

[9] Huang Fenshi. Higher Vocational College occupation career planning and employment guidance course. Employment of college students in China, 2008, ( 13 ). 